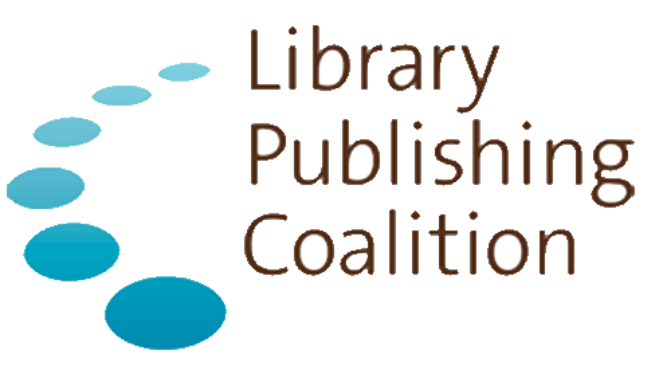

LIBRARY

PUBLISHING

COMPETENCIES

\title{
April 2020
}




\section{AUTHORS}

Created by the Library Publishing Coalition Professional Development Committee: Allison Brown, Emily Cole, Adrian Ho, Amanda Hurford, Melanie Kowalski, Ally Laird, Jessica Lange, Devin Soper, Carrye Syma; Ted Polley and Christine Fruin (Board liaisons); Melanie Schlosser (Educopia Institute)

\section{PRODUCTION}

Hannah Ballard (design) and Nancy Adams (copyediting), Educopia Institute.

\section{CITATION}

Library Publishing Coalition Professional Development Committee. (2020) Library Publishing Competencies. Atlanta, GA: Educopia Institute.

http://dx.doi.org/10.5703/1288284317123

\section{COPYRIGHT}

Library Publishing Coalition 2020. Licensed for reuse under a Creative Commons Attribution 4.0 International (CC BY 4.0) license.

\section{LEARN MORE}

The Library Publishing Coalition provides a wide variety of free resources for professional development. Learn more at Library publishing website 


\section{Table of Contents}

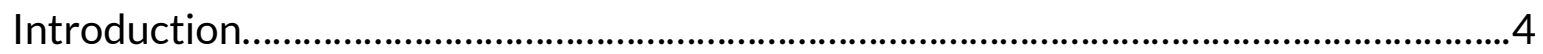

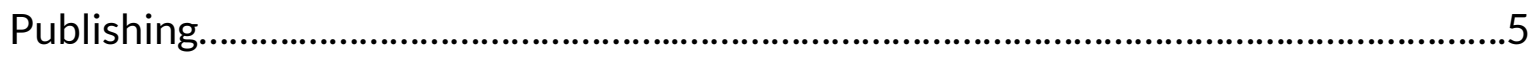

Program development and management.................................................................6

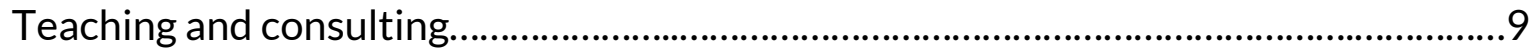




\section{Introduction}

Library publishing is a fast-changing discipline that requires Library Publishers to engage with an environment of continual learning and research in order to keep up to date on publishing practices. Due to this fast pace, a collection of guidelines and competencies to support and educate Library Publishers is a valuable asset, especially when roles or programs are newly formed, in early stages, or in transition.

This document provides a broad list of competencies that are useful in the development and provision of publishing services in libraries. The competencies are organized into three groups: publishing (the work libraries do to publish content), program development and management (the work involved in creating, managing, and sustaining a publishing program), and teaching and consulting (reflecting both the consulting work libraries do with publishing partners and their larger educational mission around publishing on campus). Each grouping begins with a brief overview, followed by a list of competencies, which are described and, in some instances, broken out into more specific areas of knowledge.

The approach of this document is holistic, rather than prescriptive, and it is unlikely that any one publishing program, let alone any one staff member, will need or be able to acquire every competency listed here. Many of the competencies are tied to particular activities and program types, so each Library Publisher can identify a subset that applies to their work.

The LPC Professional Development Committee created this document as part of their mission to provide professional development for those in the LPC membership and in the larger community of Library Publishers. The document is based on NASIG's Core Competencies for Scholarly Communication Librarians (2017), the COAR Librarians' Competencies Profile for Scholarly Communication and Open Access (2016), data from the Library Publishing Directory, committee members' experience and expertise in library publishing, and input from the Library Publishing Coalition community. Library Publishers may find it beneficial to refer to the aforementioned sources in addition to this document; in particular, we suggest referencing the NASIG report for soft skills, which are not touched on here.

We encourage the community to use this document in many ways, both in their library publishing career and for program development. For example, Library Publishers may reference the competencies when creating or seeking out professional development. Or, they may use the document to identify skills needed for new or transitioning positions. Though no one position can encompass all of these competencies, this broad list can help programs think about positions in context and identify which skills are essential to the work being performed. Finally, we encourage individual Library Publishers to use the competencies to identify both their strengths and areas in which they are interested in growing. 


\section{Publishing}

As an active participant, Library Publishers should understand and have experience with all operational aspects of the publishing process, including the setup, configuration, and maintenance of publishing platforms; the description and discoverability of content (including working with identifiers such as DOIs, ORCIDs, ISSNs, ISBNs, etc.); the establishment of publishing production processes (including accessibility); the implementation of tracking metrics and impact factors; and the methods for ensuring long-term digital preservation. Library Publishers should be accomplished project managers in order to define roles and distribute responsibilities within a library publishing program.

- Publishing platforms: Library Publishers have a variety of options when choosing a platform (or platforms) to provide publishing and hosting services. Considerations include open source vs. proprietary, hosted vs. locally-installed, budget and staff availability within the department/library, and alignment of platform capabilities with functional requirements.

- Publishing production: Publishing production includes the steps necessary to create finished, accessible scholarly materials. Library Publishers are unlikely to have expertise in all areas of publishing production, but they should be aware of the types of work that go into this process, and how to develop or outsource the skills needed to achieve their goals.

- Services such as copyediting, proofreading, layout editing, indexing, peer review, and design (typesetting/cover design) may be outsourced or require publishing partners to undertake them

- Print-on-demand (POD) technologies, institution-approved POD vendors, understanding the need for POD vs. doing a full print run for books and other publishing projects

- Accessibility, including knowledge of accessible content formats for people with disabilities and an awareness of resources for the production of accessible content

- Outsourcing, i.e., how to find qualified freelancers or external vendors when elements of the production process cannot be sustainably conducted in-house

- Description and discovery: To ensure that content can be found and used by the broadest audiences, Library Publishers need to be familiar with description and discovery best practices. 
- Relevant identifiers at the author (e.g., ORCiDs), publication (e.g., DOIs and Handles), and title (e.g., ISSNs and ISBNs) levels, and their role in publishing workflows

- Relevant metadata and XML standards, including Dublin Core, JATS, and the metadata required by aggregators such as Crossref and the Directory of Open Access Journals

- Discoverability tools and practices including scholarly indexes and search engine optimization

- Metrics: Library Publishers should understand the options and algorithms used to measure the impact of a publication in order to choose the metrics system that is right for their publications (e.g., traditional vs. altmetrics). They should also be able to explain how measures of impact differ.

- Digital preservation: In order to ensure ongoing access to content, Library Publishers should be aware of digital preservation workflows for the publications they create. They need to understand the need for and the processes involved in backup and redundancy, both at the local level and in conjunction with offsite service providers.

- Knowledge of preservation services and best practices, i.e., LOCKSS, CLOCKSS, Portico, PKP PN, LOC recommended formats, etc.

- Understanding of in-house preservation services, such as institutional repositories or local preservation solutions

\section{Program development and management}

Library Publishers should be knowledgeable about program development and management, including program sustainability, policy development, legal topics, and marketing. Skills needed for program evaluation, stakeholder development, and relationship management are also relevant. Library Publishers may also develop or evaluate agreements and contracts with publishing partners and service providers.

- Program development: Publishing programs often begin as one-off projects in response to local needs, but as those projects proliferate, they often require more planning and structure. Developing a sustainable and scalable program requires competencies in needs assessment, planning, publishing formats, acquisition workflows, and more. Library Publishers need to make decisions about what services they can and cannot offer based on available program resources (staff and/or funds).

- Stakeholder development and relationship management: Library Publishers exist within campus ecosystems and the broader publishing community. As such, developing 
positive relationships with stakeholders and maintaining those relationships is integral to the continued success of Library Publishers, both in terms of demonstrating their relevance and value and also in responding to the needs of stakeholders. Relationships should be fostered with a range of stakeholders, including library administration, campus administration, university press administration (if applicable), local IT providers, faculty and other publishing partners, the publishing community, content creators, and platform vendors.

- Policy development: Library Publishers should consider the needs of the community when developing policies. Policy decisions to be addressed may be related to a variety of areas.

- Copyright

- Author and user rights

- Open access licensing

- Preservation

- Publishing scope in content and formats

- Diversity, equity, and inclusion

- Accessibility

- Retraction or withdrawal of content

- Privacy

- Familiarity with library and institutional services integration: Publishing programs benefit from a good understanding of the library and institutional services already in place and how the programs can build mutually beneficial relationships with those services.

- Institutional repositories, including encouraging authors to submit their material here

- University presses (UP), including a basic understanding of UP culture and how to establish library publishing practices that are complementary to the UP rather than competitive

- Resources and services for storage, metadata, cataloguing, and digital preservation already in place on campus

- ORCID integration (e.g., for editors and authors) and education about its importance

- DOI registration

- Education about research metrics, including the advantages and limitations of both traditional metrics and altmetrics

- Education about author rights and open licensing, with comparison between copyright transfer and copyright retention 
- Collaboration with the teaching and learning center to promote the authoring and publication of open educational resources

- Open access and authors' rights: As an alternative to commercial scholarly publishers, Library Publishers typically embrace the principles of open access and authors' rights. Accordingly, they should be familiar with publishing processes and legal mechanisms for supporting these principles, such as publishing works under Creative Commons licenses so that authors not only retain copyright but also provide broad reuse rights to readers.

- Applying library values and ethical standards to publishing work: Library Publishers should understand and apply standards of integrity, both for publishers and authors within library publishing. LPC's Ethical Framework recommends standards for proper publishing practice with regard to diversity, equity, and inclusion as well as accessibility and rights surrounding intellectual freedom.

- Legal topics: Library Publishers are not expected to have in-depth legal expertise, but they should be familiar with the types of legal issues that arise in publishing work, know how to access expertise in this area, and know when it is necessary to seek legal counsel.

- Copyright and licensing, including knowledge of Creative Commons licenses and copyright, or familiarity with copyright resources on campus

- Contracts and terms of use, including understanding of the role of contracts in the publishing process; for example, the granting or transfer of intellectual property rights through publication agreements

- Understanding of the doctrine of fair use or fair dealing in the context of published work; ability to guide authors in determining whether or not these doctrines apply to the inclusion of third-party works in specific contexts

- Understanding of rights and permissions; ability to guide authors in seeking permission to include third-party works in their contributions in cases where fair use/fair dealing does not apply

- Marketing: Program services and content should be marketed throughout the community. Library Publishers should be aware of and use all available technologies to make content visible and discoverable.

- Awareness of on-campus services and media outlets

- Ongoing presence on social media with new posts about published contents, if possible

- Increasing the findability of published contents through library's discovery tools and through indexing by DOAJ, academic databases, WorldCat, etc.

- Facilitating online access through search engine optimization and good metadata about the published contents 
- Raising a journal's profile through periodic announcements of new issues or articles on listservs and social media

- Creation of a memorable "brand" identity with the use of a logo and/or tagline

- Program sustainability: New and established programs require careful planning to achieve sustainability, defined here to mean that program resources and staffing are stable and well matched with program and partner needs. Skill in evaluating and implementing appropriate business models and dealing with budgets is invaluable.

- Evaluation: Library Publishers should strive for regular assessment of publishing programs using metrics and stakeholder feedback to reveal the efficiency, effectiveness, and impact of current practices and use of available resources. The results will become the baseline for improvement and/or potential growth of the programs.

- Stability of financial support and expenses

- Number of contributors and contributions in a fiscal year

- Production turnaround time \& volume of published contents

\section{Teaching and consulting}

Library Publishers should be prepared to provide their publishing partners with consultations on a variety of scholarly publishing issues. Typically this means meeting with publishing partners to discuss the issues and assessing partners' level of understanding. If necessary, Library Publishers subsequently set up meetings and/or workshops to deepen the publishing partners' knowledge in these areas so that the publishing partners will be able to address the issues properly. Library Publishers should provide referrals when appropriate to ensure that publishing partners will learn from individuals with the required professional expertise.

- Teaching/consulting skills in publication development: Library Publishers should provide education on topics related to the services they offer. For example, if journal hosting is an offering, resources on using any provided software or on managing peer review would be appropriate. Additionally, Library Publishers should provide consultations to stakeholders on publishing best practices and available resources to help guide them as they prepare to publish their content.

- Copyright, author rights, fair use (or fair dealing), and open licensing

- Journal start-up processes

- Peer review process best practices, different ways to conduct peer review, the workflow for the online editorial management system (if applicable), building a peer review network/locating peer reviewers

- Accessibility, including format options and available resources for creating accessible content 
- Publishing business model options, including subscriptions, open access, APCs, etc.

- Reputation management and marketing, e.g., how to get indexed by DOAJ, etc.

- Working with students: One of the unique aspects of library publishing is its integration with the teaching and learning aspects of the parent institution (often a college or university or a cultural heritage institution with an educational mission). Library Publishers can contribute to student learning by employing students in publishing roles, publishing student work, and collaborating with faculty members to design publishing-related experiences for classes. In all cases, the Library Publisher should be familiar with the opportunities and challenges of working with students, as well as the structures and incentives that will best support student engagement in publishing. 